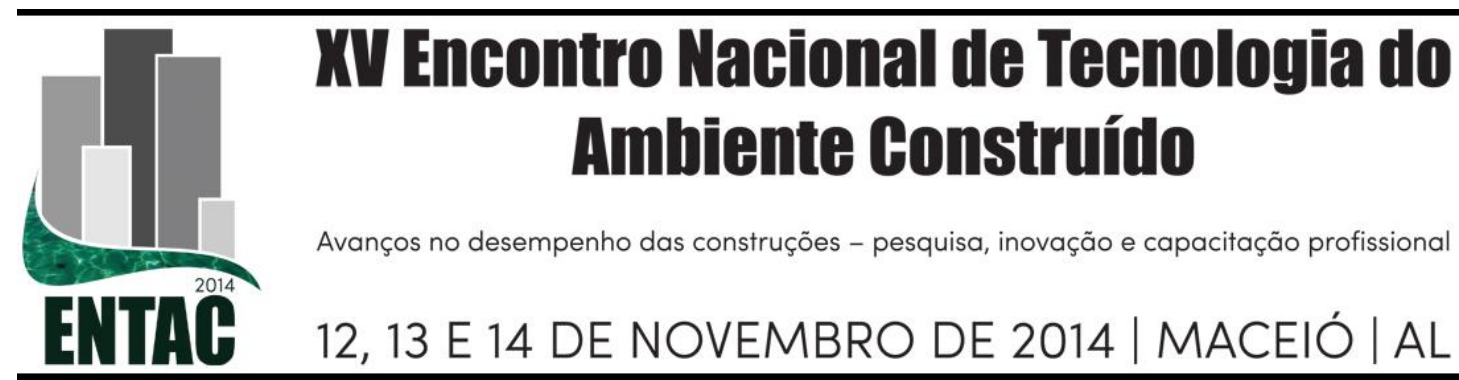

\title{
ANÁLISE DO GERENCIAMENTO DE SUBCONTRATOS DE UMA CONSTRUTORA DE MACEIÓ-AL
}

\section{SOUZA, José Roberto de Farias (1); SILVA JÚNIOR, Carlos André Vieira (2); MENDES, Olga Beatriz Barbosa (3); VALERIANO, Maria Caroline Souza (4); VASCONCELOS, David Branco Uchoa (5); WEBER, Ismael (6)}

(1) Universidade Federal de Alagoas, e-mail: fsjoseroberto@gmail.com, (2) Universidade Federal de Alagoas, e-mail: cavsjunior94@gmail.com, (3) Universidade Federal de Alagoas, e-mail:

olga_bbm@hotmail.com, (4) Universidade Federal de Alagoas, e-mail: maria.caroline@ outlook.com, (5) Universidade Federal de Alagoas, e-mail: davidu.vasconcelos@gmail.com, (6) Universidade Federal de

Alagoas, e-mail: isma.weber@gmail.com

\begin{abstract}
RESUMO
Os subcontratos vêm sendo utilizados na construção civil como uma forma de aumentar a competitividade das construtoras, gerando um serviço, teoricamente, mais eficiente e com melhor qualidade, equipes mais treinadas e qualificadas (CHOMA, 2007). Entretanto, não é isso que se observa na prática deste setor. Devido a grande informalidade nesta área e a busca incessante pela diminuição de custos, as construtoras acabam contratando essas empreiteiras indevidamente, apenas pelos preços baixos, sem as devidas análises de documentação e histórico das mesmas. Aliado a isso, os empreendimentos são realizados sem planejamento adequado, o que dificulta a geração de acordos consistentes e de fiscalização eficaz desse tipo de contrato, o que culmina em atrasos e retrabalhos no empreendimento. Dessa maneira, o presente trabalho visa analisar o gerenciamento dos subcontratos de uma construtora, desde a etapa da definição das atividades que serão terceirizadas até a etapa do distrato, passando pelo processo de seleção desses empreiteiros, análise de toda a documentação e histórico desta empresa, firmamento do contrato, execução do serviço e fiscalização do mesmo por parte da construtora, controlando assim, as condições da subcontratada de cumprir o contrato e de atender a todas às normas vigentes para o setor. O trabalho é um estudo de caso e a metodologia a ser seguida para a realização deste consistiu em revisão bibliográfica e em reuniões com os responsáveis pelas obras analisadas; na sequência, foram coletados os dados através da aplicação da lista de verificação elaborada pelos pesquisadores e gerados resultados quantitativos e qualitativos da política de gestão de empreiteiros nesta construtora. Percebeu-se que os empreiteiros atenderam a cerca de $88 \%$ dos itens abordados na lista de verificação. Entretanto, por outro lado, percebeu-se negligências em uma série de documentos no ato da contratação, bem como na fiscalização por parte da subcontratada às normas pertinentes.
\end{abstract}

Palavras-chave: Gerenciamento de Subcontratos, Custo, Lista de Verificação.

\begin{abstract}
Subcontracts have been used in construction as a way to increase the competitiveness of contractors, generating a service, theoretically, more efficient and with better quality, more trained and qualified teams (CHOMA, 2007). However, this is not what is observed in practice in this sector. Due to the great informality in this area and the relentless pursuit of lower costs, construction companies end up hiring these contractors improperly, just for the low prices, without proper analysis and historical documentation of their. Allied to this, the constructions are performed without proper planning, which makes it difficult to generate consistent agreements and effective supervision of this type of contract, culminating in delays and rework in business. Thus, this study aims to analyze the management of a construction company's subcontracts, since the step of defining the activities to be outsourced to the stage of mistreatment, through the selection process of these contractors, review of all documentation and history of this company, firmament of the contract, execution of the service and inspection of the same by
\end{abstract}


the builder, thus controlling the conditions of the subcontractor to fulfill the contract and meet all existing standards for this industry. The methodology to be followed for conducting the present study consists of literature review and meetings with the responsible for the works analyzed; after that, the data are collected by applying the checklist developed by the researchers, and generated quantitative and qualitative results of management's policy of contractors on the analyzed builder, which fulfilled about $88 \%$ of the items addressed in the checklist, however, this company still has neglected a significant number of documents at the time of hiring, also the monitoring by the subcontractor to the standards and it does not have a database of services that which were previously contracted.

Keywords: Subcontract Management, Cost, Checklist.

\section{REFERENCIAL TEÓRICO}

O mercado da construção civil vem passando por uma fase de ascensão. Segundo o Instituto Brasileiro de Geografia e Estatística (IBGE), este setor representou, nos últimos anos, uma média percentual em torno de $6 \%$ do PIB total do país (GOMES et al.,2010). O resultado desta expansão demanda em um aumento dos serviços terceirizados, que são, teoricamente, de melhor qualidade, gerando uma diminuição no cronograma da obra, bem como a diminuição do retrabalho e desperdício, bastante elevado no setor. Isto acontece devido à concorrência feroz que existe entre as empresas construtoras, que força cada vez mais o mercado a uma diminuição dos custos de produção (CHOMA, 2005).

No que se refere à mão de obra para a produção de edifícios, persiste uma situação bastante indesejável quanto aos índices de desperdício observados em obras brasileiras. A má formação dos operários, somada a má gestão desta mão de obra, gera retrabalho e ociosidade, que pode explicar parte das perdas encontradas (ARAÚJO, 2000 apud ARAÚJO; SOUZA, 2001). Segundo Maeda e Souza (2003), o conceito de produtividade não abrange somente a agilidade com que o processo de produção está sendo realizado, mas a maneira eficiente com que se produz determinado produto ou serviço, podendo ser abordado nos diversos níveis hierárquicos de uma empresa.

De acordo com Serra e Franco (2001), há um relacionamento entre contratantes e contratados que buscam, de um modo geral, o aumento da flexibilidade empresarial, a redução de custos, o incremento da produtividade e competitividade e a transferência de riscos através da delegação de atividades para operários especializados nas suas funções. Essa estratégia é comumente chamada de subcontratação ou terceirização. Portanto, dois momentos são fundamentais nesse processo e que precisam ser mais discutidos: a decisão de subempreitar e a gestão dos subempreiteiros (SERRA; FRANCO, 2001).

A pressa na contratação dos empreiteiros decorrente da diminuição dos prazos de execução das obras, que muitas vezes faz com que os gerentes, arquitetos ou engenheiros residentes ignorem etapas importantes na contratação dos prestadores de serviço. Pode-se citar a cobrança e análise da documentação pertinente para o tipo de serviço e a elaboração de um contrato que seja seguro e coerente para ambos os envolvidos, o que evita muitos transtornos no futuro. Isso acontece, geralmente, porque as contratações (sejam de empreiteiros ou fornecedores) não são incluídas no plano geral da obra, ou seja, não existe um período planejado para contratação e mobilização dos empreiteiros. Em muitos contratos, mesmo com certo planejamento, isso não é possível, principalmente no setor de obras industriais (CHOMA, 2005). É necessário, porém, o correto conhecimento e entendimento de vários aspectos teóricos e jurídicos da administração da empresa para que a tomada de decisão seja feita de forma consciente e objetiva. Porém, um grande número de falhas de um subcontrato pode ser 
decorrente de escolhas mal feitas. Por outro lado, há inúmeros casos em que bons empreiteiros celebram contratos inapropriados e, como consequência, apresentam um grande número de problemas e falhas (SERRA; FRANCO, 2001).

O mercado da construção civil ainda sofre as consequências da informalidade, não só no que diz respeito ao emprego de funcionários sem registro em carteira, mas também na falta de documentação dos mais diversos tipos, como: procedimentos de execução, padrões de qualidade, metodologia de planejamento e formalização das relações contratuais com os empreiteiros. Assim como é preciso encontrar tempo para efetuar o planejamento da obra, deve-se formalizar o contrato com o empreiteiro antes que a equipe subcontratada comece a trabalhar na obra, o que expõe a construtora a um grande risco. $\mathrm{O}$ contrato proporciona à construtora uma segurança maior em relação ao que foi contratado, possibilitando, muitas vezes, que o pagamento do empreiteiro seja suspenso se ele não comprovar o pagamento de impostos e de encargos trabalhistas de seus funcionários ou, se a obra estiver atrasada. Para que isso ocorra, é indispensável que a construtora também cumpra com o que foi acordado (CHOMA, 2005).

\section{MÉTODO DE PESQUISA}

O presente trabalho se utiliza do estudo de caso, que auxilia em uma melhor compreensão de processos organizacionais, como é o caso do tema abordado. Segundo Yin (2001), o estudo de caso é uma estratégia de pesquisa que compreende um método que abrange todo o processo analisado por meio de abordagens especificas de coleta e análise de dados.

A pesquisa foi dividida e ordenada nas seguintes etapas, como ilustrado na figura 1:

- Revisão teórica;

- Elaboração da lista de verificação para a gestão do subcontrato;

- Coleta dos dados;

- Análise e processamento dos dados;

- Apresentação dos resultados.

\section{Figura 1 - Etapas da pesquisa}
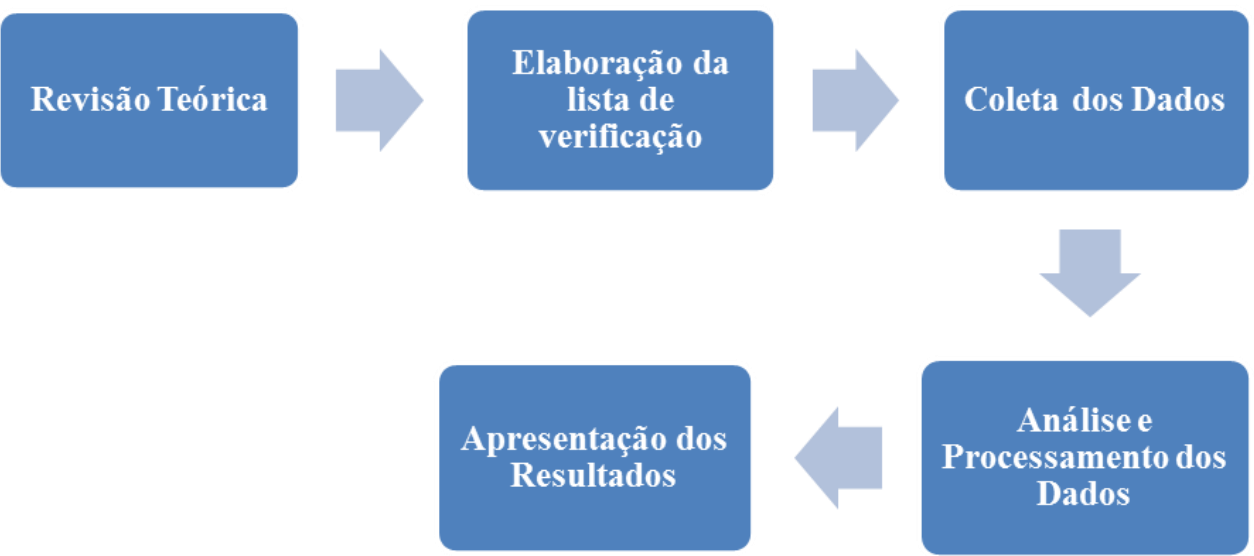

\section{Análise e}

Processamento dos Dados 
Esta metodologia foi aplicada em quatro canteiros disponibilizados como amostra por uma construtora de porte médio de Maceió-AL, do subsetor edificações da construção civil. Todos os empreendimentos são verticais e multipavimentados e cada canteiro está sob gerência de um engenheiro civil específico. A empresa em questão prioriza a subcontratação de empresas terceirizadas para os serviços com os quais tem pouca especialidade ou mão de obra. Cada um dos gestores possui certa autonomia para o firmamento de subcontratos, estando estes responsáveis pelos procedimentos de contratação estudados nessa pesquisa.

A lista de verificação utilizada foi elaborada baseada em Choma (2005) e na experiência dos pesquisadores. Os itens dessa lista foram ordenados e agrupados seguindo um modelo de gestão de subcontratos que consiste nas seguintes fases do processo contratual: planejamento e escolha da empresa terceirizada, firmamento do contrato, execução, monitoramento e, por fim, encerramento do contrato. Cada fase apresenta uma lista de perguntas ou documentos que devem ser exigidos às subcontratadas. As opções de preenchimento são "sim", "não" e "não se aplica (NA)". Em que "sim" indica que a construtora atende aos requisitos da lista de verificação, "não" descumpre os mesmos requisitos e "não se aplica" significa que o item correspondente não é pertinente para o subcontrato ou o período em questão. Além disso, a lista de verificação contempla espaço para observações descritivas. Para cada requisito abordado foi atribuído um peso, variando de 1 a 4, de acordo com a importância de cada item. Os pesos foram escolhidos considerando, com base na experiência dos pesquisadores, engenheiros entrevistados e referências bibliográficas, os riscos que o não cumprimento dos requisitos ocasiona para a relação de subcontrato e os prejuízos de produtividade e qualidade que podem afetar a obra. Por exemplo, atribuiu-se peso 3 para o item "registro de treinamentos e qualificações condizentes com o especificado pela construtora", pois foi constatado, por meio de observação de campo, que o descumprimento deste requisito implicará na diminuição da qualidade e segurança dos serviços executados, uma vez que não está comprovado em documento que os funcionários da subcontratada sejam qualificados e treinados para o serviço demandado.

A lista de verificação foi aplicada em reuniões com os engenheiros, individualmente, em cada canteiro, sendo tal aplicação baseada, principalmente, em entrevista com os gestores, ata das reuniões e documentos arquivados. Os dados coletados foram processados utilizando a plataforma Microsoft Office Excel, onde foram construídos gráficos comparativos e quantitativos por meio dos dados coletados. Tais gráficos auxiliam no entendimento da pesquisa e avaliação da gestão dos subcontratos nos canteiros da construtora em análise.

\section{RESULTADOS E DISCUSSÕES}

Através das análises e processamento dos dados coletados nos quatro canteiros, foi possível constatar que, mesmo compondo uma só empresa, as obras possuem gerenciamentos desiguais no que diz respeito à gestão de subcontratadas. A empresa estudada está $88 \%$ adequada à lista de verificação aplicada, apresentando desvio padrão de 0,675 , numa escala de 0 a 10 . A figura 2 ilustra a nota individual de cada canteiro de obra avaliado. 


\section{Figura 2 - Avaliação individual dos canteiros}

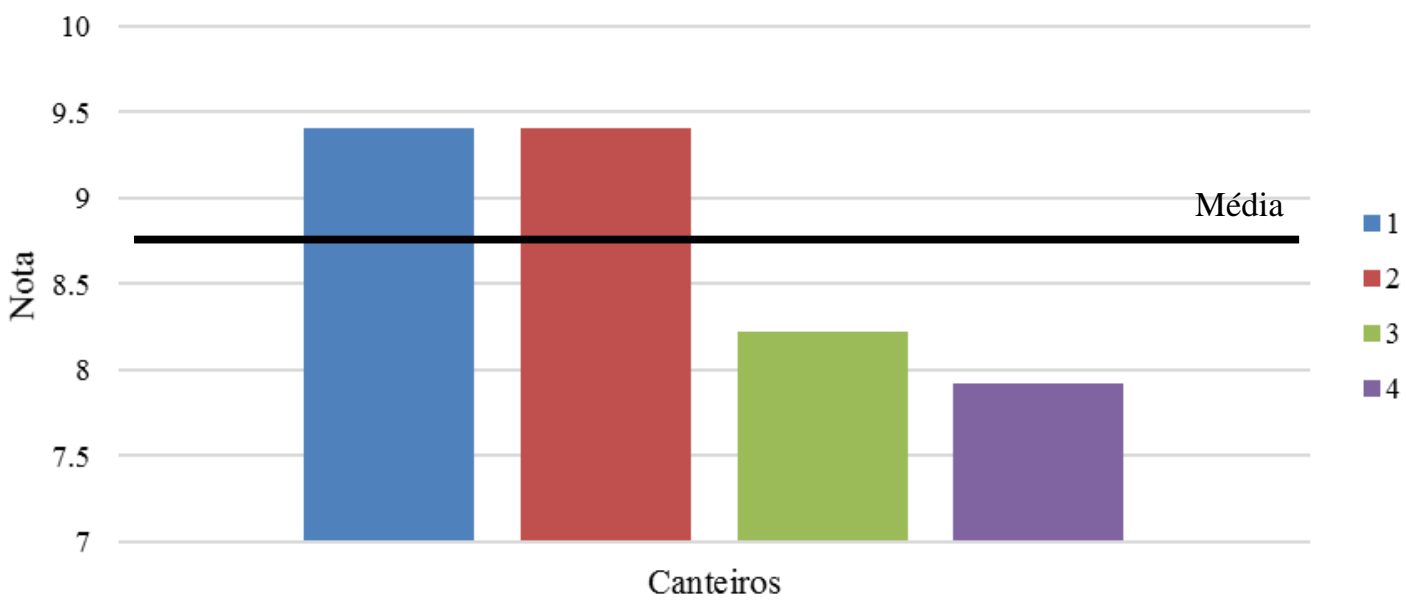

Tratando do planejamento e escolha de empresas subcontratadas, a construtora em questão procura referências de suas potenciais subcontratadas em atividades de outras construtoras e em seu próprio histórico de contratação, sendo essencial esta prática para que se conheça o trabalho das empreiteiras sob vários aspectos importantes, como o cumprimento de prazos, qualidade e desempenho no serviço prestado e a capacidade de negociação desta. Observou-se, também, que a empresa exige das empreiteiras alguns documentos que são adequados aos parâmetros atuais do mercado da região. Entretanto, negligencia outros documentos que são importantes para o sucesso do subcontrato. No entanto, a construtora não possui um banco de dados no qual estes serviços sejam armazenados quando finalizados, o que pode ser uma falha, pois negligencia uma experiência importante, principalmente, quando busca retomar o contrato com a empreiteira em outros empreendimentos.

No ato da cotação das subcontratadas, constatou-se que os documentos exigidos pela construtora se resumem à cópia do cartão do Cadastro Nacional de Pessoa Jurídica (CNPJ) e contrato social, possibilitando que os construtores obtenham informações de quanto tempo a empreiteira tem desenvolvido atividades no mercado, nomes dos sócios, além de verificar se a empresa possui as devidas atribuições às quais se propõe a realizar. Entretanto, a construtora não exige as certidões negativas da Justiça do Trabalho, de débito do SINDUSCON, de débito do SINTRACON e a certidão simplificada da junta comercial que garantirão o comprometimento da subcontratada com encargos sociais e impostos trabalhistas, além do envolvimento destas com os sindicatos do setor na região. Constatou-se que, nesta fase de contratação, não é comum à cobrança destes documentos na região e, segundo os engenheiros entrevistados, as subcontratadas alegam dificuldades e excesso de burocracia para a organização de todos os documentos supracitados. Além disso, os prazos para a cotação são curtos, o que facilita a negligência de alguns documentos fundamentais para o fechamento correto do contrato entre as partes. Desse modo, a fins de esclarecimento, o item documentação exigida foi bem avaliado pelo fato de que a grande maioria dos documentos solicitados pela construtora foram entregues pela subcontratada e os demais documentos negligenciados não foram suficientes em quantidade para redução significativa da nota do item em questão.

A Figura 3 indica que, mesmo constatadas algumas irregularidades no processo de contratação de empreiteiras, as avalições das obras analisadas se encontram em 
intervalos próximos, com dois dos canteiros obtendo notas entre 9 e 10, e a nota mínima ficando entre 7 e 8.

Figura 3 - Intervalos das notas de avaliação

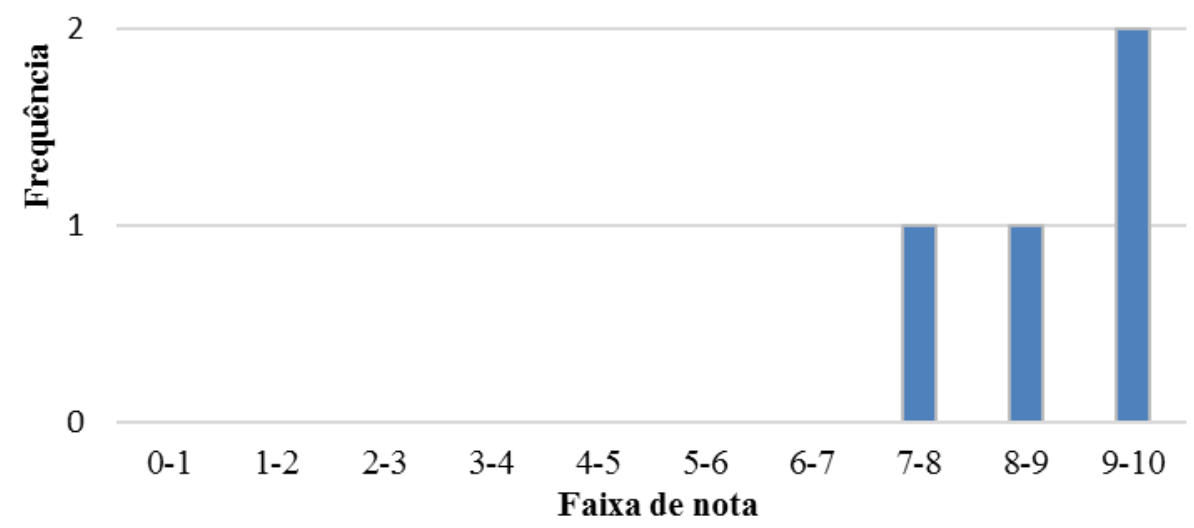

Abordando o segundo ponto da lista de verificação, elaboração do contrato, verificou-se que a construtora em questão exige uma série de documentos da subcontratada para o firmamento do contrato, e alguns destes a empreiteira se compromete a repassar periodicamente, dentre os quais se destacam: folha de pagamento dos funcionários, cartão de ponto, guia de recolhimento do Fundo de Garantia por Tempo de Serviço (FGTS) e de informações à Previdência Social (GFIP). Estes documentos são fundamentais para salvaguardar a construtora em casos de processos trabalhistas e auxilia no controle dos funcionários autorizados a circular na obra. Nesta fase de elaboração do contrato, constatou-se que a construtora especifica alguns itens fundamentais, como: objeto do contrato, obrigações da contratante e da contratada, preços, quantidades, formas de pagamento e as condições para o aceite do serviço. Estes pontos são importantes, pois detalham de que forma ocorrerá a relação comercial entre as partes e as obrigações de ambos.

Como apresentado anteriormente, as quatro obras são geridas por engenheiros diferentes e por isso possuem políticas mais particulares de gerenciamento. A Figura 4 auxilia na visualização dos principais pontos onde esses canteiros diferem na escolha de subcontratadas, apontando para o quesito planejamento, envolvendo escolha da empreiteira e checagem de documentos, como o principal ponto de dissimilaridade.

Após o firmamento do contrato, a terceirizada começa a execução do serviço demandado e, nesta fase, é essencial que haja o acompanhamento por parte da construtora. Identificou-se que os funcionários das subcontratadas não possuem a preparação adequada no que tange à segurança do trabalho, bem como as empreiteiras não possuem a prática de fiscalizar seus funcionários e respectivas atividades neste setor. Muitas vezes, nem chegam a repassar os EPI's necessários para as atividades demandadas. Este controle, então, passa a ser exercido pelos técnicos de segurança das respectivas construtoras, estando, inclusive, estes funcionários passíveis de advertência e até proibição de permanecer no canteiro, caso recorram constantemente em atos 
inseguros. Esta prática por parte das empreiteiras sobrecarrega a logística do canteiro e aumenta a probabilidade de acidentes de trabalho, sendo a construtora e o respectivo engenheiro gestor corresponsáveis nas demandas de segurança do trabalho.

Periodicamente são realizadas vistorias de qualidade, prazos e controle de desperdício de materiais por parte da construtora e estes indicadores são atualizados, mantendo-se, inclusive, quadros expostos no canteiro com o desempenho das empreiteiras em diversos aspectos. Tais atos são aconselháveis para se evitar retrabalhos e aumentar o controle sobre o cronograma da obra. No entanto, caso as subcontratadas não estejam atendendo ao especificado, são realizadas reuniões onde são elaboradas ações de correção. Essas reuniões possuem ata, que é repassada para a alta direção da construtora que, por sua vez, periodicamente vistoria os canteiros para confirmar estas ações de melhorias.

Figura 4 - Comparação peculiar entre as obras avaliadas

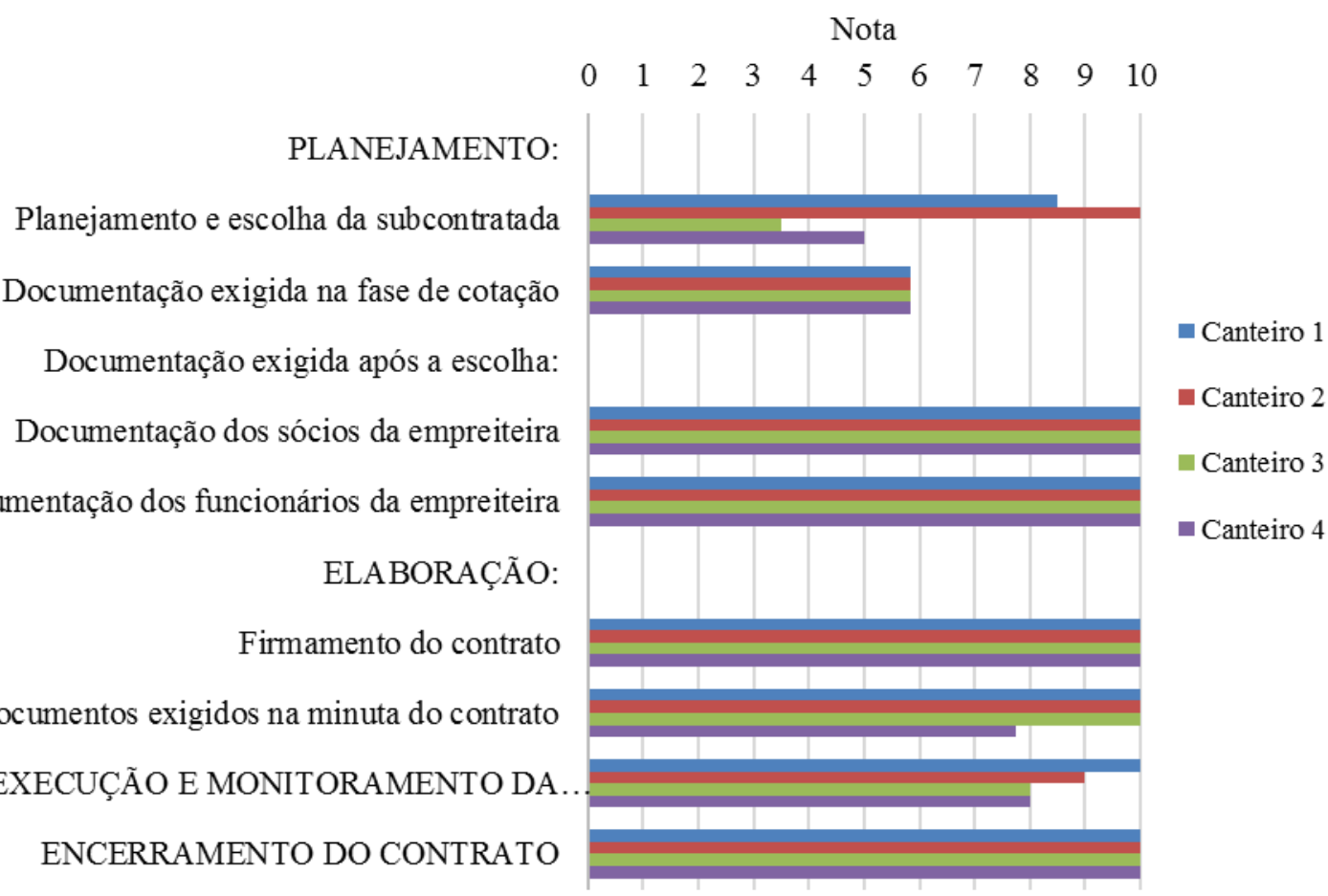

Os dados analisados mostraram também que, ao final do serviço, as partes assinam o distrato, documento este que ratifica o cumprimento do contrato e o término da relação comercial entre as empresas envolvidas. Foi constatado, também, que não é realizado uma avaliação de lições aprendidas na construtora que serviriam para alimentar um possível banco de dados de subcontratos, atividade esta que não demandaria muito tempo por parte dos gestores e que evitaria problemas futuros.

Como as quatro obras compõem a mesma empresa e objetivando a realização de uma análise geral da mesma, a Figura 5 ilustra a nota média da construtora em cada etapa do processo de contratação de empreiteiras. 
Figura 5 - Status geral da política de contratação de empreiteiras da construtora estudada

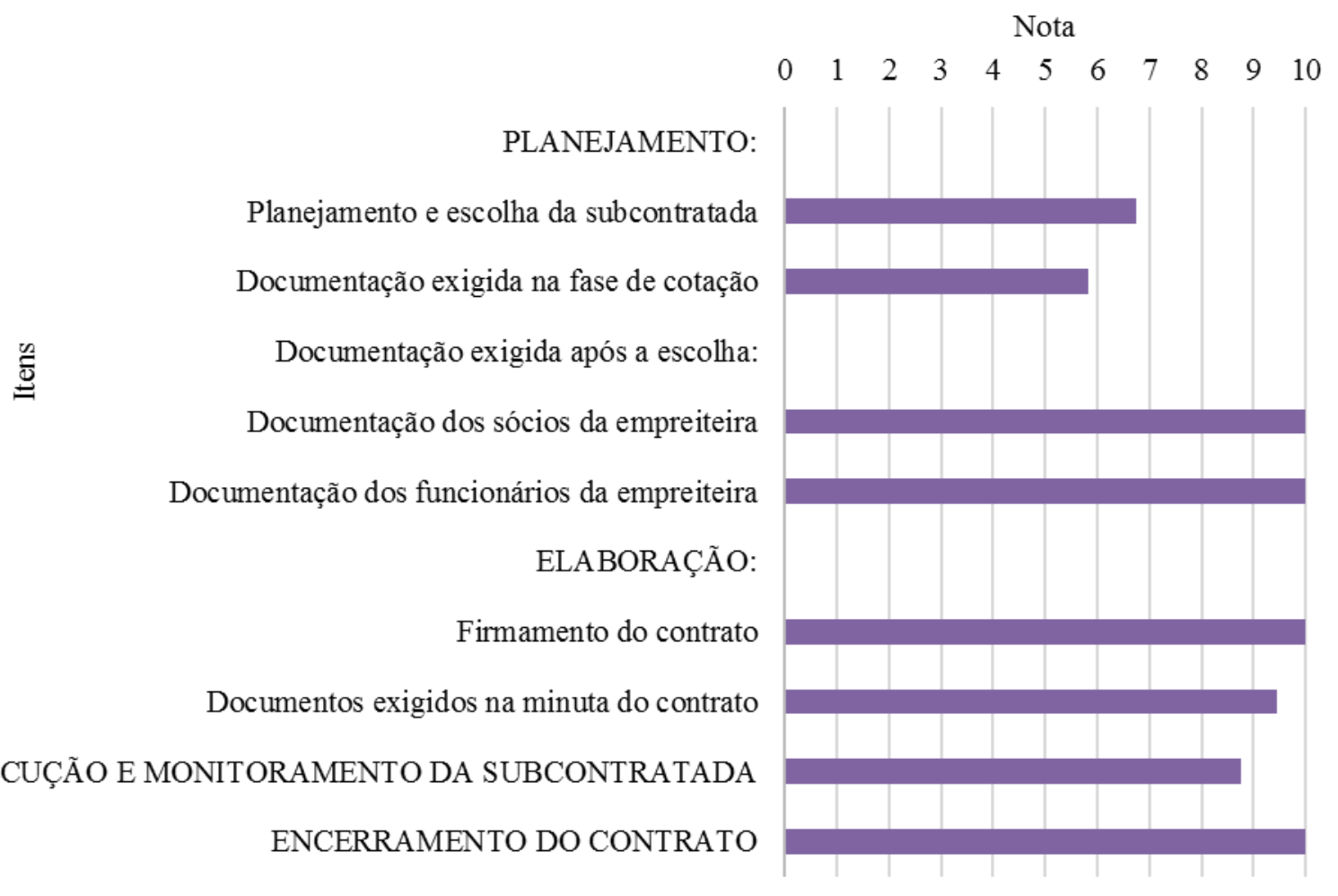

\section{CONCLUSÃO}

De acordo com o exposto anteriormente, o objetivo do trabalho foi atingido, tendo em vista que se cumpriu a análise da gestão de subcontratos em uma construtora do estado. Analisando-se os resultados, denota-se que a construtora em questão possui uma boa gerência nas diversas etapas do subcontrato, obtendo nota geral média de 8,7. Entretanto, os construtores e gestores de obras ainda negligenciam alguns itens que são de extrema importância para esse tipo de contrato, devido, principalmente, à desorganização destas subcontratadas que, geralmente, possuem uma gestão pouco eficiente.

Constatou-se, também, a falta de cultura da construtora de se elaborar um banco de dados que contenha registros do desempenho de todas as empreiteiras que já trabalharam em seus canteiros de obra. Evidencia-se que o mercado da construção ainda não exige toda a documentação pertinente para que se possa garantir total segurança durante o período do contrato. Como exemplo, para o item referente a exigência de documentação, mesmo ele sendo bem avaliado, documentos como certidão negativa e de débito não são obtidos pelas construtoras pois, regionalmente, não é item corriqueiramente solicitado.

Outro aspecto que é sugerido para gestão de subcontratos é um aumento no rigor da fiscalização e acompanhamento dos colaboradores destas empreiteiras durante a execução da obra, principalmente em relação a questões vinculadas a segurança do trabalho. 


\section{REFERÊNCIAS}

ARAÚJO, L. O. C.; SOUZA, U. E. L. Produtividade da mão de obra na execução de alvenaria: deteç̧ão e quantificação de fatores influenciadores. Boletim Técnico da Escola Politécnica da USP. BT/PMI, São Paulo, v. 1, p. 1-24, 2001.

CHOMA, A. A.; CHOMA, C. A. (2005). Como gerir contratos com empreiteiros: manual de gestão do empreiteiro na construção civil. PINI $2^{\circ}$ edição.

GOMES, R. A., VALENTE JÚNIOR, A. S., COSTA, R. A. Evolução do emprego formal no Brasil e Nordeste - Primeiro Trimestre de 2010. Escritório técnico de estudos econômicos no nordeste, Banco do Nordeste, 2010.

MAEDA, F. M.; SOUZA, U. E. L. Previsão da produtividade da mão de obra na execução de revestimento interno em gesso. Boletim Técnico da Escola Politécnica da USP. BT/PCC, São Paulo, v. 332, p. 1-16, 2003.

SERRA, S. M. B.; FRANCO, L. S. Diretrizes para gestão dos subempreiteiros. Brasil - São Paulo, SP. 2001. Boletim Técnico da Escola Politécnica da USP.

YIN, R. K. Estudo de caso - planejamento e métodos. ( $2^{\text {a }}$ Ed.). Porto Alegre: Bookman, 2001. 
ANEXO

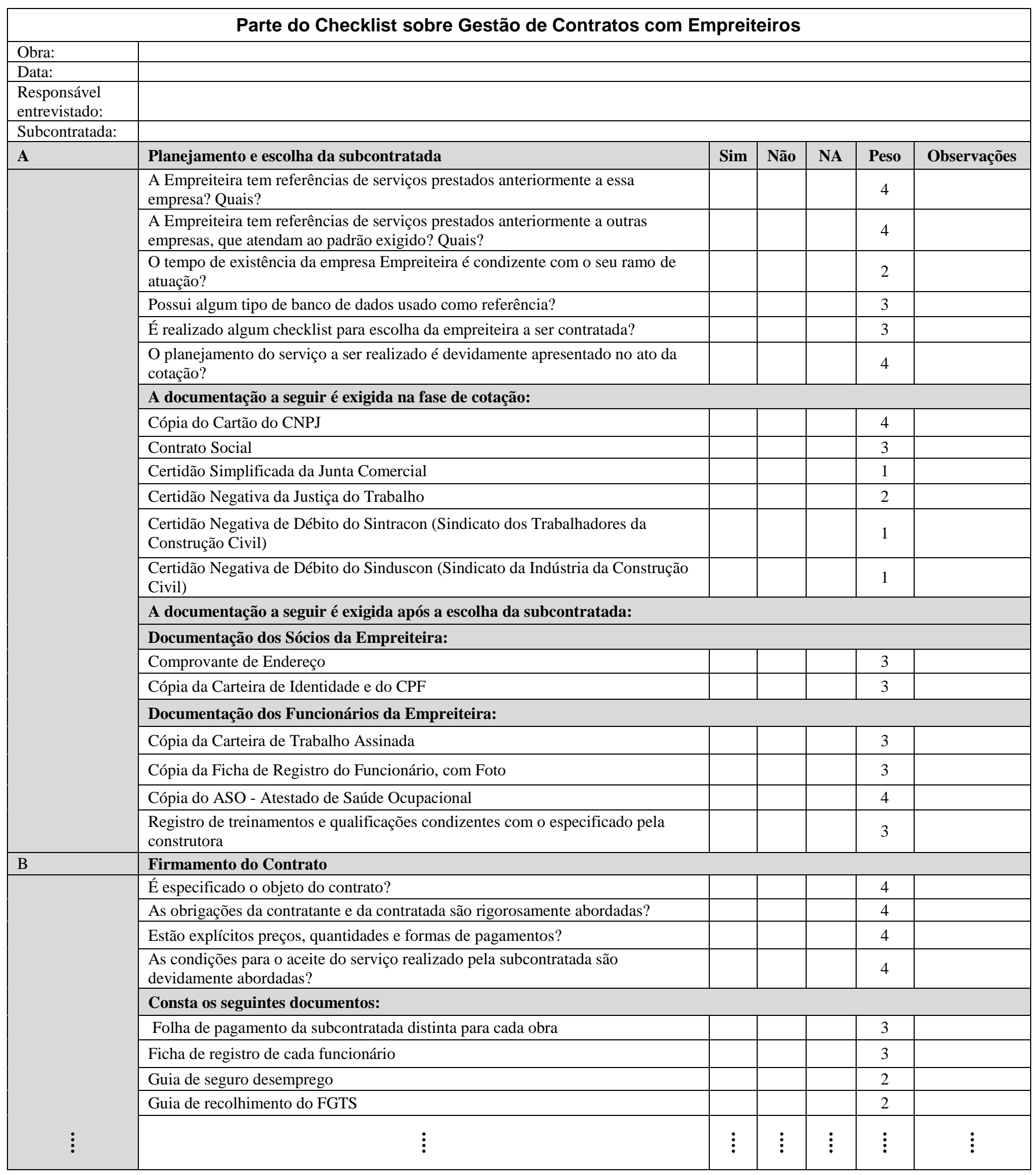

